Palay, A.J. (1982). The B* Tree Search Algorithm - New Results. Artificial Intelligence, Vol. 19, No. 2, pp. 145-163.

Parnas, D. (1988). Why Engineers Should Not Use Artificial Intelligence. INFOR Special Issue on Intelligence Integration, Vol. 26, No. 4, pp. 234-246.

Reinfeld, F. (1958). Win at Chess. Dover Publications Inc., New York.

Rivest, R.L. (1988). Game Tree Searching by Min/Max Approximation. Artificial Intelligence, Vol. 34 , No. 1, pp. 77-96.

Schaeffer, J. and Marsland, T.A. (1985). The Utility of Expert Knowledge. Proceedings International Joint Conference on Artificial Intelligence, pp. 585-587.

Schaeffer, J. (1986). Experiments in Search and Knowledge. Ph.D. thesis, Department of Computer Science, University of Waterloo.

Schaeffer, J. (1987). Speculative Computing. ICCA Journal, Vol. 10, No. 3, pp. 118-124.

Schaeffer, J. (1989). Conspiracy Numbers. Artificial Intelligence, in press. Also in Advances in Computer Chess 5 (Ed. D. Beal), Elsevier Science Publishers, pp. 199-218, 1989.

Schrüfer, G. (1988). Minimax-Suchen: Kosten, Qualität und Algorithmen. Ph.D. thesis, Technical University Braunschweig, West Germany.

Simon, H.A. and Gilmartin, K. (1973). A simulation of memory for chess positions. Cognitive Psychology, Vol. 5, pp. 29-46.

Slate, D.J. and Atkin, L.R. (1977). Chess 4.5 - The Northwestern University Chess Program. Chess Skill in Man and Machine (Ed. P.W. Frey), Springer-Verlag, New York, pp. 82-118.

\title{
KBBKN ON A MICRO
}

Hans Zellner

Mallersdorf, West Germany

\section{THE CHALLENGE ACCEPTED}

It is nearly two years ago that the Editor-in-Chief (1987) stated in a letter "Building a KBBKN database on an ATARI ST would be an almost superhuman performance." At roughly the same date, John Roycroft (1987) told me: "You are indeed ambitious, even foolhardy." Frederic Friedel (1985) wrote in his Journal CSS 4/85: "Thompson needed 700 hours on a mainframe to create the database for KBBKN. The analysis required 2,500 MBytes of disc memory." Friedel (1988) stated in CSS 2/88: "The capacity needed to create a 5-men-database is far beyond the horizon of any micro."

Well, the qualifications almost superhuman and far beyond the horizon whetted my appetite for what proved to be a hard combat indeed. Still, I am proud to state that in the first week of February 1989 I completed the analysis of KBBKN on no heavier an engine than an ATARI ST with 1 MByte of RAM and 20 MByte of hard disc. 
True, the program was written in Assembler, but was no less reliable for it. The pure time needed to create the database was some $200 \mathrm{~h}$. The elapsed time was much greater, since, for obvious reasons, I had to back up my precious data every two or three hours.

\section{THE RESULTS COMPARED}

So far, my results only showed that a five-men analysis was well within the capacity of a despised micro. It is more relevant to compare my results with Ken Thompson's who established the benchmark in the field (cf. Van den Herik and Herschberg, 1987). Generically we have a very good match. We agree in one statement and four subranges:

- The 32 win-in-66 positions (referred to the full board) are identical with those published in Roycroft (1986).

- In the ranges wins-in-(20-25), -(27-29), -31, -(35-66) agreement is perfect.

Yet, beyond the ranges mentioned, differences persist. To be sure these are minor, as exemplified by the winsin-1, which Thompson enumerates as $46,568,408$ whereas my results sum to $46,568,736$. The difference of 328 positions is no more than seven tenthousandths of a percent. This may be due to some flaw in my program possibly attributable to the complex structure of my Assembler program.

As a conclusion I submit:

- at least one five-men endgame is feasible on a modest microcomputer;

- Thompson's mainframe results have been essentially confirmed;

- such discrepancies as exist must be clarified: no such clarification will greatly upset established statistics for KBBKN.

\section{REFERENCES}

Friedel, F. (1985). Das perfekte Endspiel (2). Computerschach und Spiele, No. 4, pp. 22-25.

Friedel, F. (1988). Das perfekte Endspiel - auf Atari ST. Computerschach und Spiele, No. 2, pp. 28-31.

Herik, H.J. van den (1987). Personal communication.

Herik, H.J. van den and Herschberg, I.S. (1987). The KBBKN Statistics: New Data from Ken Thompson. ICCA Journal, Vol. 10, No. 1, pp. 39-40.

Roycroft, A.J. (1986). *C* GBR class 0023. EG, Vol. VI, No. 83, p. 12.

Roycroft, A.J. (1987). Personal communication. 